\title{
Loss of muscle mass: current developments in cachexia and sarcopenia focused on biomarkers and treatment
}

\author{
Cathleen Drescher, Masaaki Konishi, Nicole Ebner \& Jochen Springer* \\ Innovative Clinical Trials, Department of Cardiology and Pneumology, University Medical Center Göttingen (UMG), Göttingen, Germany
}

\begin{abstract}
Loss of muscle mass arises from an imbalance of protein synthesis and protein degradation. Potential triggers of muscle wasting and function are immobilization, loss of appetite, dystrophies, and chronic diseases as well as aging. All these conditions lead to increased morbidity and mortality in patients, which makes it a timely matter to find new biomarkers to get a fast clinical diagnosis and to develop new therapies. This mini-review covers current developments in the field of biomarkers and drugs on cachexia and sarcopenia. Here, we reported about promising markers, e.g. tartate-resistant acid phosphatase 5a, and novel substances like epigallocatechin-3-gallate. In summary, the progress to combat muscle wasting is in full swing, and perhaps diagnosis of muscle atrophy and of course patient treatments could be soon support by improved and more helpful strategies.
\end{abstract}

Keywords Muscle wasting; Biomarker; Treatment; Sarcopenia; Cachexia

Received: 15 September 2015; Accepted: 25 September 2015

*Correspondence to: Dr. Jochen Springer, Institute of Innovative Clinical Trials, Department of Cardiology and Pneumology, University Medical Center Göttingen, Robert-Koch-Str. 40, 37075 Göttingen, Germany. Email: jochen.springer@med.uni-goettingen.de

\section{Introduction}

Loss of muscle mass is commonly observed in chronic diseases like cancer, chronic heart failure (HF), chronic obstructive pulmonary disease, chronic kidney disease (CKD), cystic fibrosis, liver cirrhosis, Crohn's disease, rheumatoid arthritis (RA), stroke, and many neurodegenerative diseases as well as in human immunodeficiency virus/acquired immune deficiency syndrome, malaria, and tuberculosis. ${ }^{1-3}$ A serious complication of these chronic illnesses is cachexia. Cachexia is defined as weight loss greater than $5 \%$ of body weight in 12 months or less in the presence of chronic illness or as a body mass index (BMI) lower than $20 \mathrm{~kg} / \mathrm{m}^{2}$. In addition, usually three of the following five criteria are required: decreased muscle strength, fatigue, anorexia, low fat-free mass index, increase of inflammation markers such as Creactive protein or interleukin (IL)-6 as well as anaemia or low serum albumin. ${ }^{4,5}$ Loss of muscle mass and function, especially muscle strength and gait speed, associated with aging occurs in sarcopenia. ${ }^{6,7}$ Indeed, sarcopenia, cachexia, and malnutrition are considered as the main causes of muscle wasting ${ }^{8}$ and affect millions of elderly people and patients. ${ }^{9}$ Moreover, muscle atrophy can develop independently from diseases and age through disuse of the muscles. ${ }^{10}$ For a better classification and common language in medical science for 'muscle wasting disease' there is a proposal to combine the concepts of muscle wasting, sarcopenia, frailty, and cachexia by disease aetiology and disease progression. ${ }^{8}$ Patients with muscle atrophy show decreased muscle strength and therefore reduced quality of life, which is caused by a lower activity and increased exercise intolerance. ${ }^{11}$ In sarcopenic patients, muscle wasting is frequently associated with loss of bone, which leads to a higher risk of hip and other fractures. ${ }^{12}$ Hip fracture also results in loss of musculature because of disuse atrophy. ${ }^{13}$ All these conditions lead to increased morbidity and mortality in patients, ${ }^{14}$ and therefore developments in biomarkers and treatment finding to improve patients' lives is necessary (for schematic representation of the process see 
Figure 1). The reason for muscle atrophy is an imbalance of protein synthesis and protein degradation. Three major protein degradation pathways play a role in development of muscle wasting: (1) activation of the ubiquitin-proteasome-system (UPS), (2) apoptosis through caspase signalling, and (3) autophagy. $^{15}$

\section{Current developments on muscle mass loss}

The UPS pathway, which is conserved from yeast to mammals, plays a major role in degradation of most short-lived proteins. Most targets are cell cycle regulatory proteins as well as misfolded proteins. The target proteins undergo an ATP-dependent ubiquitination marking the protein for degradation. Polyubiquinated proteins are subsequently degraded by the proteasome ${ }^{16}$ while monoubiquitinated substrates are eliminated in lysosomes. ${ }^{17}$ At the beginning of the reaction, ubiquitin binds to an ubiquitin activating enzyme (E1) and forms a thio-ester bond. This reaction allows ubiquitin to transfer to an ubiquitin conjugating enzyme (E2) followed by the formation of an isopeptide bond which finally leads to the binding of E2 to an ubiquitin ligase (E3). The ligase specifically recognizes the substrate protein and transfers ubiquitin to the target protein. ${ }^{18}$ Subsequently, the target proteins are unfolded and degraded by an ATP-dependent process. ${ }^{19}$ Two muscle-specific E3 ubiquitin ligases named muscle atrophy Fbox (MAFbx, atrogin-1) and muscle RING finger-1 (MuRF-1) were first described in 2001 and are significantly up-regulated during muscle atrophy. ${ }^{20,21}$ However, the loss of these E3ligases only leads to partial protection against muscle wasting. ${ }^{20}$ MAFbx was shown to target regulatory factors for protein synthesis like $M_{y o D^{22}}$ and the eukaryotic initiation factor of protein synthesis elF3-f. ${ }^{23}$ MuRF-1 binds to titin $^{24,25}$ and is targeting to myofibrillar proteins like myosin heavy chain, myosin light chain, and myosin-binding $\mathrm{C}^{26} \mathrm{An}$ other muscle-specific ubiquitin ligase named tripartite motif 32 (TRIM32) was discovered in 2005. ${ }^{27}$ TRIM32 is thought to ubiquitinate the thick myofibrillar filament as well as actin and dysbindin. ${ }^{27} \mathrm{~A}$ muscle-specific F-box protein was foun in $2007,{ }^{28}$ which induces the ubiquitination of insulin receptor substrate 1 thereby providing a negative feedback on the IGF1R/IRS1/PI3K/Akt pathway by early signal termination. ${ }^{29}$ In addition 2010, tumour necrosis factor (TNF) receptorassociated factor has been found to play a critic al role in atrophy as an E3 ubiquitin ligase. ${ }^{30}$

Cancer cachexia animal models are showing significant wasting of the myocardium. ${ }^{31-33}$ In one study it was shown that the heart muscle weight is decreased by $20 \%$ on average. $^{34}$ In another cancer cachexia study, cardiac wasting was associated with left-ventricular (LV)-dysfunction. ${ }^{35}$ Treatment with selected agents (bisoprolol, spirolactone, and imidapril) used in HF resulted in placebo-treated group of $\mathrm{AH}-130$ rats in a loss of $21 \pm 2 \%$ LVmass while the LVmass was stabilized

Figure 1 Muscle mass loss is caused by many reasons resulting in morbidity and mortality which makes it necessary to find appropriate biomarkers and treatment strategies to improve patient's quality of life.

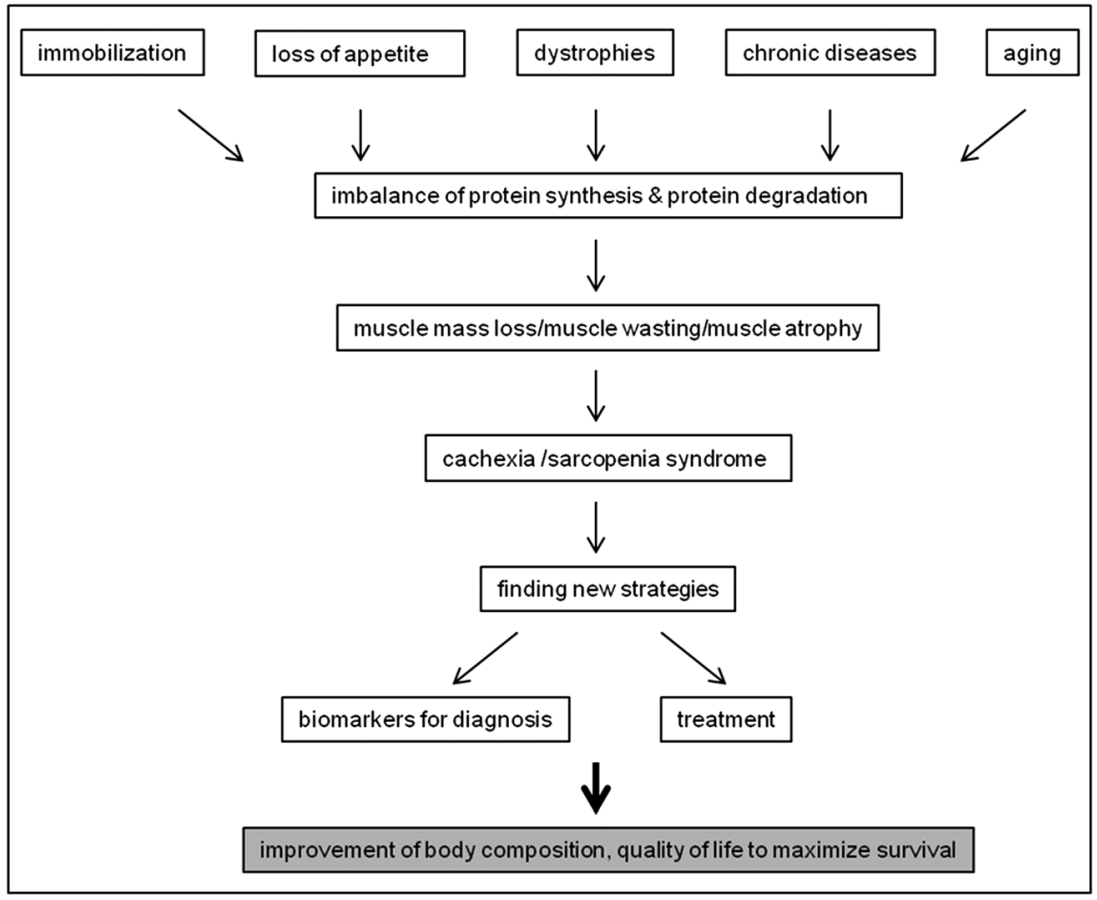


by bisoprolol $(+2 \pm 8 \%, P<0.0001)$ and increased by spirolactone $(+9 \pm 3 \%, P<0.0001)$ whereas imidapril had no effect. $^{35}$ Moreover, a decrease in the trypsin-like activity of the UPS was seen in bisoprolol and spirolactone-treated animals in contrast to imidapril which enhanced proteasome activity. ${ }^{35}$ However, under oxidative stress conditions an upregulated expression level of the ubiquitin ligases MAFbx and MURF-1 in cachectic hearts leads to the induction of the UPS. ${ }^{34}$ MAFbx and MuRF-1 are elevated as well at the mRNA level linked to the degradation of cardiac troponin I, $\alpha$-actin-2, and MyoD which is leading to impaired contractility. ${ }^{36}$ Furthermore, another study showed a reduced heart rate and fractional shortening using echocardiography in the myocardium of cancer cachectic mice. ${ }^{37}$ Elevated levels of reactive oxygen species in cachectic skeletal muscle have been linked to an activation of the UPS. ${ }^{38}$ In general, cytokines including IL-1, IL-6, TNF- $\alpha$, and interferon- $\gamma$ have been shown to contribute a catabolism net in skeletal muscle and to form a state of oxidative stress. ${ }^{39}$ These cytokines lead to an activation of nuclear factor kappa-light-chain-enhancer of activated B-cells (NF $\mathrm{B}$ ) and forkhead transcription factors (FoxO) in muscle ${ }^{40}$ resulting in increased proteolysis by inducing the expression of MAFbx and MuRF-1. ${ }^{15}$ The involvement of the $\mathrm{NF} \kappa \mathrm{B}$ pathway was originally observed in a model of disuse atrophy ${ }^{41}$ where it binds directly to the MuRF-1. ${ }^{42}$ Furthermore, increased oxidative stress activates the NF $\kappa$ B pathway. ${ }^{43}$ Surprisingly, an inhibition of $\mathrm{NF} \kappa \mathrm{B}$ via the IkappaB kinase complex only partially rescues the phenotype of the cachectic gastrocnemius in a murine model of cancer cachexia. ${ }^{44}$ The FoxO family members consist of three isoforms as FoxO1, FoxO3, and FoxO4. It was shown that FoxO1 and FoxO3a are significantly up-regulated in cachectic muscles from Lewis Lung Carcinoma ${ }^{45}$ and Colon 26 tumour-bearing mice ${ }^{46}$; FoxO1 is also up-regulated in skeletal muscle in human cancer cachexia patients. ${ }^{47}$ Thus, these findings strongly support the involvement of $\mathrm{NF} \kappa \mathrm{B}$ and FoxO in the process of muscle atrophy. However, mitochondrial dysfunction and loss of mitochondria in skeletal muscle contribute to disrupted muscle function. ${ }^{48}$ Indeed, investigations with markers of mitochondrial function and activity like the mitochondrial enzymes pyruvate dehydrogenase (PDH) and the cytochrome $c$ oxidase (COX) showed that the protein concentrations of $\mathrm{PDH}$ and $\mathrm{COX}$ in the skeletal muscle of colon cancer patients were decreased and a lower activity of PDH was observed as well. $^{49}$

Despite a large number of studies, our understanding of the development of muscle wasting and the involved pathways remains very limited. For instance, in some diseases like RA muscle wasting is not well investigated yet, ${ }^{50-52}$ but better understanding is imperative for designing further studies and to develop new therapies. A recent study was aimed at an evaluation of muscle atrophy in skeletal muscle in a mouse model of RA and to establish a relation between disease score and muscle wasting. ${ }^{53}$ Findings implicated the existence of a progressive development of muscle wasting with an early onset, which was especially associated with increased serum levels of cytokines, e.g. IL-6. ${ }^{53}$ Another not well-studied muscle wasting disease is stroke, although it is known that stroke rapidly leads to an increase in muscle loss. ${ }^{54}$ Hence, it is difficult to treat muscle atrophy in stroke patients. However, a large prospective stroke study with the main objectives to study changes in body composition, and metabolic and functional changes of muscle tissue in patients with acute ischemic stroke is underway. ${ }^{55}$ This study unites the knowledge of neurologists, cardiologists, and endocrinologists, and their findings might improve rehabilitation after stroke. Generally, impaired feeding, reduced caloric intake, and loss of appetite lead to a negative nutritional and nitrogen balance, ${ }^{56,57}$ and immobilization causes physical inactivity and muscle atrophy after stroke. ${ }^{58,59}$ It has been shown that elevated volumes of TNF- $\alpha$ are responsible for muscle loss and that plasma concentrations of the enzyme visfatin were significantly elevated in patients after ischemic stroke. ${ }^{60,61}$ For that, investigations to changes of inflammation parameters and its relation to body composition, insulin sensitivity, and patient's survival will be made as well. ${ }^{55}$

\section{Current news on biomarker research}

Exact quantification of skeletal muscle mass is challenging. To better determine skeletal muscle mass, many measurement methods were developed in the last two centuries (for a historical overview see ${ }^{62}$ ). Since the early 1970 s computed tomography, magnet resonance imaging, and dual-energy $\mathrm{X}$ ray absorptiometry came into application. ${ }^{62} \mathrm{~A}$ problem of these methods is that they are all expensive and thus only available at larger institutions. Moreover, these methods are only able to detect tissue wasting, but they are incapable to show the risk of developing muscle atrophy. ${ }^{63,64}$ But there is described a practical screening tool in a validated model to improve screening for low skeletal muscle mass in older adults. ${ }^{65}$ It has been suggested that the BMI is strongly associated with a low skeletal muscle mass index which could be helpful for primary care settings and treating elderly populations at risk of sarcopenia. ${ }^{65}$ However, it is imperative to find new robust biomarkers, which are cheap and easily available for diagnosis and therapy monitoring in clinics. ${ }^{64}$ Potential candidates are summarized in Table 1 and are described in more detail below. Serum creatinine may be such a reliable, cheap, and easily accessible biomarker of skeletal muscle mass in human subjects, for example in CKD patients. ${ }^{66}$ The adaption of the liquid chromatography-tandem mass spectrometry based on $\mathrm{D}_{3}$-creatine dilution method from an oral dose and detection of urinary creatinine enrichment by isotope ratio mass spectrometry ${ }^{79}$ could be an accurate tool to measure total body creatine skeletal muscle mass change. ${ }^{80}$ 
Table 1 Emerging candidates for biomarkers for cachexia and sarcopenia

\begin{tabular}{|c|}
\hline Emerging biomarkers for cachexia and sarcopenia \\
\hline $\begin{array}{l}\text { Creatinine }^{66} \\
\text { Neoepitope }^{67} \\
\text { MMP-generated degradation fragment of collagen } 6(\mathrm{C} 6 \mathrm{M})^{68} \\
\text { Type VI collagen N-terminal globular domain epitope (IC6) } \\
\text { N-terminal propeptide of type III procollagen (P3NP) } \\
\text { C-terminal agrin fragment (CAF) } \\
{\text { Methyl- } \text { d }_{3} \text {-Methylhistidine (D-3MH) }}^{70} \\
\text { Growth differentiating factor-15 (GDF-15) }^{71} \\
\text { Follistatin (FST) } \\
\text { Irisin }^{72} \\
\text { Ghrelin }^{73} \\
\text { Leptin }^{73} \\
\beta \text {-Dystroglycan } \\
\text { Dystrophin }^{74} \\
\text { Tartrate-resistant acid phosphatase } 5 a(\text { TRACP5a })^{75-78}\end{array}$ \\
\hline
\end{tabular}

MMP, matrix metalloproteinase.

The drawback of this method is the high cost and limited availability of the necessary machinery. Furthermore, serological neoepitopes have been suggested as muscle wasting biomarkers to solve some of these problems mentioned before. Neoepitopes do not reflect a condition or state like creatinine reflecting muscle mass, but a process which allows an early detection of a muscle loss in disease. In fact, neoepitope biomarkers are parent proteins that are produced through post-translational modifications, i.e. glycosylation, phosphorylation, acetylation, nitrosylation, methylation, and ubiquitination of an existing molecule and are formed by protease cleavage or addition of chemical groups in tissues of interest. ${ }^{67}$ The most common parent proteins for muscle loss biomarkers are sarcomeric proteins (e.g. myosin, actin, troponin, and tropomyosin) and components of the extracellular matrix (e.g. laminins). ${ }^{67}$ That makes neoepitopes interesting to be biomarkers of muscle pathology. ${ }^{67}$ Other serological biomarker candidates for muscle wasting are type VI collagen turnover-related peptides. ${ }^{68}$ In a study, blood was analysed for levels and their correlation of following biomarkers: a matrix metalloproteinase-generated degradation fragment of collagen 6 (C6M) and a type $\mathrm{VI}$ collagen $\mathrm{N}$ terminal globular domain epitope (IC6). ${ }^{68}$ These fragments can only be considered biomarker candidates of muscle mass and change in young men but not in elderly men. ${ }^{68}$ However, circulating biomarkers like the N-terminal propeptide of type III procollagen (P3NP) and C-terminal agrin fragment (CAF) respond to resistance exercise training in older adults. ${ }^{69}$ Short-time resistance exercise training (6 weeks) improves leg extension muscle strength, measured on a knee lift, by $29 \%$ from $39.7 \pm 16.5$ to $51.1 \pm 18.3 \mathrm{~kg}$ in the exercise group $(P<0.001)$ and muscle quality by $28 \%$ from $3.64 \pm 0.85$ to $4.67 \pm 0.81$ relative strength (leg extension strength in $\mathrm{kg} / \mathrm{lean}$ quadriceps muscle mass in $\mathrm{kg}$ ) in the exercise group $(P<0.001)$ in older adults and may result in changes P3NP and $\mathrm{CAF}^{69}$ Indeed, CAF appears to increase in response to short-time resistance exercise training in older adults in contrast to P3NP where the results were less clear. ${ }^{69}$ P3NP showed a positive correlation to changes in lean body mass ( $r=0.422, P=0.045)$, and there was observed a positive correlation between change in circulating CAF and change in cross-sectional area of the vastus lateralis $(r=0.542$, $P=0.008){ }^{69}$ However, P3NP is associated with subsequent changes in lean body mass and appendicular skeletal muscle mass and seems to be a useful early predictive biomarker of anabolic response to growth hormone and testosterone. ${ }^{81} 3$ Methylhistidine $(3 \mathrm{MH})$ has been proposed as a marker of myofibrillar proteolysis through post-translational methylation of specific histidine residues in actin and myosin. ${ }^{82-85}$ In a clinical scenario, $3 \mathrm{MH}$ has to be determined quantitatively in urine or plasma collections. A major disadvantage is that meat intake for 3 days prior to sample collection of patients can disturb the analysis of $3 \mathrm{MH}$. A study from 2013 used $3 \mathrm{MH}$, which was labelled with an isotope by using a non-radioactive isotope-based strategy. $^{70}$ The labelled methyl- $d_{3}-3 \mathrm{MH}(\mathrm{D}-3 \mathrm{MH})$ was taken orally by healthy men, and urine and plasma samples were collected next day over 5-6h, and were analysed for $\mathrm{D}-3 \mathrm{MH}$ enrichment by gas chromatography-mass spectrometry. ${ }^{70}$ The results suggest that it is possible to obtain an index of myofibrillar protein breakdown in urinary or plasma samples and that it is not necessary to quantify urine and plasma collections or to have an abstinence from meat for several days. ${ }^{70}$ Growth differentiating factor-15 (GDF-15) plays an important role in muscle wasting and cachexia. ${ }^{86}$ Results from studies suggest that GDF-15 induces weight and muscle loss, which makes GDF-15 a promising marker of cachexia and muscle atrophy. ${ }^{71}$ Myostatin is a known negative regulator of muscle growth and mass, which is associated with muscle wasting ${ }^{86}$ suggesting it as putative marker for muscle atrophy. However, this could not be confirmed in humans. ${ }^{87}$ Interestingly, follistatin (FST), an endogenous, strong inhibitor of myostatin-mediated muscle wasting, has been suggested as a potential biomarker in sarcopenia. ${ }^{72}$ FST binds to myostatin in the serum, thus, making myostatin often undetect$a^{2 b l e}{ }^{88}$ and moreover, FST-overexpressing transgenic mice have been shown a significant increase in muscle mass. ${ }^{89}$ Therefore, FST seems to be a positive regulator of muscle growth which makes it interesting to be a biomarker. Irisin, the extracellular cleaved product of fibronectin type III domain containing protein 5 , seems to be a potential sarcopenia biomarker, because of its involvement in muscle physiology. ${ }^{72}$ Plasma levels and mRNA expression of irisin were found to be elevated in mice in response to exercise. ${ }^{90}$ Moreover, a positive correlation between circulating irisin and FST levels has been described in healthy men and obese persons. ${ }^{91}$ Other than inflammatory cytokines, like IL-1, IL-6, and TNF- $\alpha$, which are associated with anorexia and weight loss, ${ }^{92,93}$ hormonal factors have been postulated to play a role in development in muscle loss, especially in cachexia. ${ }^{94,95}$ Such factors include for instance leptin, ${ }^{96}$ ghrelin, ${ }^{97}$ and obestatin ${ }^{98}$ which are all thought to play a major role in cancer cachexia. These emerging biomarkers were 
investigated in oncologic patients as diagnostic and/or predictive markers, as well as their impact on patient survival. ${ }^{73}$ The study showed that ghrelin and leptin may be promising biomarkers for the identification of cachexia related to cancer and mark survival in cancer patients. ${ }^{73}$ Ghrelin serum levels were significantly higher in cancer patients in comparison to healthy subjects (573.31 \pm 130 vs. 320.20 $\pm 66.48 \mathrm{ng} / \mathrm{ml}, P<0.0001)$ and levels of leptin were significantly lower in cancer patients than in healthy controls $(38.4 \pm 21.2$ vs. $76.28 \pm 17.48 \mathrm{ng} / \mathrm{ml}, P<0.0001) .^{73}$ Ghrelin correlated negatively with leptin $(r=-0.75 ; P<0.0001)$ and inverse as well. ${ }^{73}$ By Kaplan Meier analysis, the survival prediction was tested, and it was shown that patients with the best profile were those with low levels of ghrelin associated with high levels of leptin and on the contrary patients with high ghrelin levels and low levels of leptin had a minor survival probability (log-rank $\left.\left(\chi^{2}\right) 8.02 ; P=0.004\right) .{ }^{73}$ Furthermore, in a recently published study, in which a large number of putative biomarker candidates were tested, with a cohort of upper gastrointestinal cancer patients, $\beta$-dystroglycan was identified as a potential biomarker for weight-loss and myosin heavy chain or dystrophin as survival biomarkers. ${ }^{74}$ As mentioned before, inflammatory cytokines are used for prognosis of cancer cachexia. A new promising chronic inflammatory marker was found recently and is suggested to play a prognostic role in cancer cachexia: the tartrateresistant acid phosphatase 5 a (TRACP5a). ${ }^{75}$ Moreover, it is already known that serum TRACP5a is elevated in patients with $\mathrm{RA}^{76}$ and that the protein level of TRACP5a is reflected in cardiovascular diseases and sarcoidosis. ${ }^{77,78}$

\section{Current news on treatment}

In 2013 and 2014, many new biomarkers, as described before, were investigated in different diseases and models. But although many researchers and pharmaceutical companies tried to find therapies for muscle atrophy, including cachexia and sarcopenia, no solution has been established until now. $^{71,99,100}$ Interestingly, Morley et al. discussed if we are closer to having drugs for treatment muscle wasting disease and therefore drugs were highlighted, which showed current advances in therapy for sarcopenia and cachexia (e.g. ghrelin agonists, selective androgen receptor molecules, megestrol acetate, activin receptor antagonists, espindolol, and fast skeletal muscle troponin inhibitors). ${ }^{101}$ Indeed, Morley et al. postulated that there is a remarkable increase in the knowledge of muscle wasting diseases because of new studies. However, a general strategy to avoid muscle mass loss and function is exercise. ${ }^{102,103}$ Evidence of positive effects on fraility and sarcopenia through exercising are emerging. ${ }^{102,104-108}$ Recently, an exercise investigation focused on muscle quality in men and women aged 50 years and older suggested that long-term exercise, especially resistance exercise, is beneficial for muscle quality. ${ }^{109}$ Interestingly, people over 60 years, who perform aerobic exercise once a week, also show positive association to muscle quality. ${ }^{109}$ In rat skeletal muscle, an example for a successful result of exercising was postulated for glycogen synthase kinase-3 $\beta$ (GSK-3), which has a big therapeutical potential when it is inhibited. ${ }^{110} \mathrm{An}$ inhibition of the constitutively active kinase GSK-3 $\beta$ is considered to be beneficial, as it is involved in the regulatory inactivation of many anabolic pathways often leading to muscle wasting. ${ }^{111-116}$ In detail, it has been demonstrated that physical exercise significantly decreases GSK-3 $\beta$ activity in rat skeletal muscle within $10 \mathrm{~min}$ of exercise and remained depressed with 30 and 60 min of exercise. ${ }^{110}$ In the following part current treatment substances discoveries will be listed (see for detailed therapies ${ }^{117,118}$ ).

Ghrelin, which was delineated as a good biomarker before, $^{73}$ and its analogues BIM-28125 and BIM-28131 seem to have a beneficial effect after administration in a rat HF study. ${ }^{119}$ In that animal model it was shown that the expression of myostatin and the TNF- $\alpha$ concentration are significantly reduced in the gastrocnemius after treatment. ${ }^{119}$ Moreover in a pre-clinical study, treatment with a ghrelin receptor agonist, named anamorelin, showed a significant and dose-dependent increased food intake as well as body weight compared with the vehicle control in healthy rats. ${ }^{120}$ Thereby, with a treatment of anamorelin, a significant increase of growth hormone and insulin-like growth factor-1 plasma levels was observed in healthy female pigs in comparison to the placebos, ${ }^{120}$ which makes anamorelin a potential drug for treatment of cancer anorexia-cachexia syndrome. Espindolol, an anabolic catabolic transforming agent, was used in a sarcopenia rat study. ${ }^{121}$ Espindolol itself is a nonspecific $\beta$ - 1 and $\beta$-2 adrenergic receptor blocker with intrinsic sympathomimetic activity on the $\beta-2$ adrenergic receptor which results in reduced catabolism and increased anabolism, and espindolol is a highly potent antagonist of 5-HT1A receptors which has an effect on food-intake as well as reduced fatigue and thermogenesis. ${ }^{122}$ A recent study, the ACT-ONE trial, which was a multicentre, randomized, double-blind, and placebo-controlled study for dose-finding of espindolol in cachectic patients with non-small cell lung cancer and colorectal cancer in stages III and IV was started. ${ }^{122}$ At the 7th Cachexia Conference, the first results of the ACT-ONE trial with 87 patients from 17 centers were presented. ${ }^{86}$ Patients were treated with two doses of espindolol twice daily for 16 weeks. The results showed that the higher dose improves lean and fat mass, and the that handgrip strength is significantly increased at both doses. ${ }^{86}$ Interestingly, in a rat sarcopenia model, espindolol treatment only had a small effect on overall body weight, but did significantly increase lean body mass, while at the same time reducing fat mass. This makes espindolol an attractive candidate for treating sarcopenic patients, as these patients are often obese. ${ }^{121} \mathrm{~A}$ highly potent 
$\beta-2$ adrenoceptor-selective agonist, formoterol, was used as a drug in a cancer cachexia rat model, and it significantly reduced muscle wasting but had no influence on heart weight and function as often described in literature. ${ }^{123}$ Epigallocatechin3-gallate (EGCg), which is a component of green tea, was published to be an effective inhibitor of increased protein degradation and depressed protein synthesis in an in vitro study by using murine $\mathrm{C}_{2} \mathrm{C}_{12}$ myotubes. ${ }^{124} \mathrm{EGCg}$ is not an approved drug but acts as a nutritional support and has been shown to attenuate skeletal muscle wasting in the Lewis lung carcinoma model of cancer cachexia. ${ }^{125}$

\section{Conclusions}

Muscle loss arises from a dysbalance of catabolism and anabolism, i.e. protein degradation and protein synthesis. Despite a large number of studies, knowledge of disease related muscle wasting remains unclear. But investigations in the last two years like studies focused on $\mathrm{RA}^{53}$ and stroke $\mathrm{e}^{55}$ bring us one step ahead in understanding processes of muscle wasting because of those diseases. Cachectic and sarcopenic patients often suffer from quality of life including appetite loss and lower muscle strength, which makes finding appropriate biomarkers for diagnosis of muscle wasting associated diseases a timely matter. Although an 'ideal' marker has not yet been identified, the development of some emerging candidates (Table 1) promise much potential. Neoepitopes ${ }^{67}$ as biomarkers could be the solution for early diagnosis of a potential muscle mass loss allowing earlier detection and treatment to prevent morbidity and mortality in patients. In addition, finding new treatment strategies and drugs has to be developed to treat patient's symptoms. There are some very promising investigational drugs in studies related to cachexia and sarcopenia, but further research is necessary for a transition into the clinic. Maybe there is the need to combine existing treatment strategies with further novel approaches to treat muscle mass loss.

\section{Disclosure}

This paper is also published in parallel in the International Journal of Cardiology.

\section{Acknowledgments}

The authors certify that they comply with the ethical guidelines for authorship and publishing of the Journal of Cachexia, Sarcopenia, and Muscle (von Haehling S, Morley JE, Coats AJS, Anker SD. Ethical guidelines for authorship and publishing in the Journal of Cachexia, Sarcopenia, and Muscle. J Cachexia Sarcopenia Muscle. 2010;1:7-8.)

\section{Conflict of interest}

Cathleen Drescher, Masaaki Konishi, Nicole Ebner, and Jochen Springer declare that they have no conflict of interest.

\section{References}

1. Mak RH, Ikizler AT, Kovesdy CP, Raj DS, Stenvinkel P, Kalantar-Zadeh K. Wasting in chronic kidney disease. I Cachexia Sarcopenia Muscle 2011;2:9-25.

2. Onwuamaegbu ME, Henein M, Coats AJ. Cachexia in malaria and heart failure: therapeutic considerations in clinical practice. Postgrad Med J 2004;80:642-649.

3. von Haehling S, Lainscak M, Springer J, Anker SD. Cardiac cachexia: a systematic overview. Pharmacol Ther 2009;121:227-252.

4. Fearon K, Strasser F, Anker SD, Bosaeus I, Bruera E, Fainsinger RL, Jatoi A, Loprinzi C, MacDonald N, Mantovani G, Davis M, Muscaritoli M, Ottery F, Radbruch L, Ravasco P, Walsh D, Wilcock A, Kaasa S, Baracos VE. Definition and classification of cancer cachexia: an international consensus. Lancet Oncol 2011;12:489-495.

5. Evans WJ, Morley JE, Argiles J, Bales C, Baracos V, Guttridge D, Jatoi A, KalantarZadeh K, Lochs H, Mantovani G, Marks $D$, Mitch WE, Muscaritoli M, Najand A, Ponikowski P, Rossi Fanelli F, Schambelan
M, Schols A, Schuster M, Thomas D, Wolfe R, Anker SD. Cachexia: a new definition. Clin Nutr 2008;27:793-799.

6. Rosenberg IH. Sarcopenia: origins and clinical relevance. Clin Geriatr Med 2011;27:337-339.

7. Clark BC, Manini TM. Sarcopenia =/= dynapenia. J Gerontol A Biol Sci Med Sci 2008;63:829-834.

8. Anker SD, Coats AJ, Morley JE, Rosano G, Bernabei $R$, von Haehling $S$, KalantarZadeh K. Muscle wasting disease: a proposal for a new disease classification. J Cachexia Sarcopenia Muscle 2014;5:1-3.

9. Farkas J, von Haehling S, Kalantar-Zadeh K, Morley JE, Anker SD, Lainscak M. Cachexia as a major public health problem: frequent, costly, and deadly. J Cachexia Sarcopenia Muscle 2013;4:173-178.

10. Brooks NE, Myburgh KH. Skeletal muscle wasting with disuse atrophy is multidimensional: the response and interaction of myonuclei, satellite cells and signaling pathways. Front Physiol 2014;5:99.
11. von Haehling $\mathrm{S}$. The wasting continuum in heart failure: from sarcopenia to cachexia. Proc Nutr Soc 2015;12:1-11.

12. Ormsbee MJ, Prado CM, Ilich JZ, Purcell S, Siervo M, Folsom A, Panton L. Osteosarcopenic obesity: the role of bone, muscle, and fat on health. J Cachexia Sarcopenia Muscle 2014;5:183-192.

13. Villani AM, Miller MD, Cameron ID, Kurrle S, Whitehead C, Crotty M. Development and relative validity of a new field instrument for detection of geriatric cachexia: preliminary analysis in hip fracture patients. J Cachexia Sarcopenia Muscle 2013;4:209-216.

14. Kalantar-Zadeh K, Rhee C, Sim JJ, Stenvinkel P, Anker SD, Kovesdy CP. Why cachexia kills: examining the causality of poor outcomes in wasting conditions. J Cachexia Sarcopenia Muscle 2013;4:89-94.

15. Glass DJ. Signaling pathways perturbing muscle mass. Curr Opin Clin Nutr Metab Care 2010;13:225-229. 
16. Chau V, Tobias JW, Bachmair A, Marriott D, Ecker DJ, Gonda DK, Varshavsky A. A multiubiquitin chain is confined to specific lysine in a targeted short-lived protein. Science 1989;243:1576-1583.

17. Marmor MD, Yarden Y. Role of protein ubiquitylation in regulating endocytosis of receptor tyrosine kinases. Oncogene 2004;23:2057-2070.

18. Passmore LA, Barford D. Getting into position: the catalytic mechanisms of protein ubiquitylation. Biochem J 2004;379:513-525.

19. Attaix D, Ventadour S, Codran A, Bechet D, Taillandier D, Combaret L. The ubiquitin-proteasome system and skeletal muscle wasting. Essays Bioche 2005;41:173-186.

20. Bodine SC, Latres E, Baumhueter S, Lai VK, Nunez L, Clarke BA, Poueymirou WT, Panaro FJ, Na E, Dharmarajan K, Pan ZQ, Valenzuela DM, DeChiara TM, Stitt TN, Yancopoulos GD, Glass DJ. Identification of ubiquitin ligases required for skeletal muscle atrophy. Science 2001;294:1704-1708.

21. Gomes MD, Lecker SH, Jagoe RT, Navon A, Goldberg AL. Atrogin-1, a muscle-specific F-box protein highly expressed during muscle atrophy. Proc Natl Acad Sci U S A 2001;98:14440-14445.

22. Tintignac LA, Lagirand J, Batonnet $S$, Sirri V, Leibovitch MP, Leibovitch SA. Degradation of MyoD mediated by the SCF (MAFbx) ubiquitin ligase. I Biol Chem 2005;280:2847-2856.

23. Lagirand-Cantaloube J, Offner N, Csibi A, Leibovitch MP, Batonnet-Pichon S, Tintignac LA, Segura CT, Leibovitch SA. The initiation factor elF3-f is a major target for atrogin1/MAFbx function in skeletal muscle atrophy. Embo J 2008;27:1266-1276.

24. Centner T, Yano J, Kimura E, McElhinny AS, Pelin K, Witt CC, Bang ML, Trombitas K, Granzier H, Gregorio CC, Sorimachi H, Labeit S. Identification of muscle specific ring finger proteins as potential regulators of the titin kinase domain. J Mol Biol 2001;306:717-726.

25. McElhinny AS, Kakinuma K, Sorimachi $H$, Labeit S, Gregorio CC. Muscle-specific RING finger-1 interacts with titin to regulate sarcomeric $\mathrm{M}$-line and thick filament structure and may have nuclear functions via its interaction with glucocorticoid modulatory element binding protein-1. $J$ Cell Biol 2002;157:125-136.

26. Cohen S, Brault JJ, Gygi SP, Glass DJ, Valenzuela DM, Gartner C, Latres E, Goldberg AL. During muscle atrophy, thick, but not thin, filament components are degraded by MuRF1-dependent ubiquitylation. J Cell Biol 2009;185:1083-1095.

27. Kudryashova E, Kudryashov D, Kramerova I, Spencer MJ. Trim32 is a ubiquitin ligase mutated in limb girdle muscular dystrophy type $2 \mathrm{H}$ that binds to skeletal muscle myosin and ubiquitinates actin. $J \mathrm{Mol} \mathrm{BiO}$ 2005;354:413-424.

28. Ye J, Zhang $Y, X u$ J, Zhang $Q$, Zhu $D$. FBXO40, a gene encoding a novel muscle-specific F-box protein, is upregulated in denervation-related muscle atrophy. Gene 2007;404:53-60.
29. Shi J, Luo L, Eash J, Ibebunjo C, Glass DJ. The SCF-Fbxo40 complex induces IRS1 ubiquitination in skeletal muscle, limiting IGF1 signaling. Dev Cell 2011;21:835-847.

30. Paul PK, Gupta SK, Bhatnagar S, Panguluri SK, Darnay BG, Choi Y, Kumar A. Targeted ablation of TRAF6 inhibits skeletal muscle wasting in mice. J Cell Biol 2010;191:13951411.

31. Acharyya S, Ladner KJ, Nelsen LL, Damrauer J, Reiser PJ, Swoap S, Guttridge DC. Cancer cachexia is regulated by selective targeting of skeletal muscle gene products. J Clin Invest 2004;114:370-378.

32. Cosper PF, Leinwand LA. Cancer causes cardiac atrophy and autophagy in a sexually dimorphic manner. Cancer Res 2011;71:1710-1720.

33. Costelli P, De Tullio R, Baccino FM, Melloni E. Activation of $\mathrm{Ca}(2+)$-dependent proteolysis in skeletal muscle and heart in cancer cachexia. Br J Cancer 2001;84:946-950.

34. Hinch EC, Sullivan-Gunn MJ, Vaughan VC, McGlynn MA, Lewandowski PA. Disruption of pro-oxidant and antioxidant systems with elevated expression of the ubiquitin proteosome system in the cachectic heart muscle of nude mice. I Cachexia Sarcopenia Muscle Dec 2013;4:287-293.

35. Springer J, Tschirner A, Haghikia A, von Haehling S, Lal H, Grzesiak A, Kaschina E, Palus $S$, Potsch $M$, von Websky K, Hocher $B$, Latouche C, Jaisser F, Morawietz L, Coats AJ, Beadle J, Argiles JM, Thum T, Foldes $\mathrm{G}$, Doehner W, Hilfiker-Kleiner D, Force T, Anker SD. Prevention of liver cancer cachexia-induced cardiac wasting and heart failure. Eur Heart $J \mathrm{Apr}$ 2014;35:932-941.

36. Adams $V$, Linke A, Wisloff $U$, Doring $C$, Erbs S, Krankel N, Witt CC, Labeit S, Muller-Werdan U, Schuler G, Hambrecht R. Myocardial expression of Murf-1 and MAFbx after induction of chronic heart failure: Effect on myocardial contractility. Cardiovasc Res 2007;73:120-129.

37. Tian M, Nishijima $Y$, Asp ML, Stout MB, Reiser PJ, Belury MA. Cardiac alterations in cancer-induced cachexia in mice. Int $J$ Oncol 2010;37:347-353.

38. Gomes-Marcondes MC, Tisdale MJ. Induction of protein catabolism and the ubiquitin-proteasome pathway by mild oxidative stress. Cancer Lett 2002;180:69-74.

39. Barreiro $E$, de la Puente $B$, Busquets $S$, Lopez-Soriano FJ, Gea J, Argiles JM. Both oxidative and nitrosative stress are associated with muscle wasting in tumour-bearing rats. FEBS Lett 2005;579:1646-1652.

40. De Larichaudy J, Zufferli A, Serra F, Isidori AM, Naro F, Dessalle K, Desgeorges $M$, Piraud $M$, Cheillan D, Vidal $H$, Lefai $E$, Nemoz G. TNF-alpha- and tumor-induced skeletal muscle atrophy involves sphingolipid metabolism. Skelet Muscle 2012;2:2.

41. Hunter RB, Stevenson $E$, Koncarevic A, Mitchell-Felton $H$, Essig DA, Kandarian SC. Activation of an alternative NFkappaB pathway in skeletal muscle during disuse atrophy. Faseb J Apr 2002;16:529-538.
42. Cai D, Frantz JD, Tawa NE Jr, Melendez PA, Oh $B C$, Lidov $H G$, Hasselgren PO, Frontera WR, Lee J, Glass DJ, Shoelson SE. IKKbeta/ NF-kappaB activation causes severe muscle wasting in mice. Cell 2004;119:285-298.

43. Powers SK, Kavazis AN, McClung JM. Oxidative stress and disuse muscle atrophy. J Appl Physiol (1985) 2007;102:2389-2397.

44. Der-Torossian H, Wysong A, Shadfar S, Willis MS, McDunn J, Couch ME. Metabolic derangements in the gastrocnemius and the effect of Compound A therapy in a murine model of cancer cachexia. J Cachexia Sarcopenia Muscle 2013;4:145-155.

45. Reed SA, Sandesara PB, Senf SM, Judge AR. Inhibition of FoxO transcriptional activity prevents muscle fiber atrophy during cachexia and induces hypertrophy. Faseb J 2012;26:987-1000.

46. Cornwell EW, Mirbod A, Wu CL, Kandarian SC, Jackman RW. C26 cancer-induced muscle wasting is IKKbeta-dependent and NF-kappaB-independent. PLoS One 2014;9 e87776:.

47. Skorokhod A, Bachmann J, Giese NA, Martignoni ME, Krakowski-Roosen $\mathrm{H}$. Real-imaging CDNA-AFLP transcript profiling of pancreatic cancer patients: Egr1 as a potential key regulator of muscle cachexia. BMC Cancer 2012;12:265.

48. Romanello $V$, Guadagnin E, Gomes L, Roder I, Sandri C, Petersen Y, Milan G, Masiero E, Del Piccolo P, Foretz M, Scorrano L, Rudolf $R$, Sandri M. Mitochondrial fission and remodelling contributes to muscle atrophy. Embo J 2010;29:1774-1785.

49. Phillips BE, Smith K, Liptrot S, Atherton PJ, Varadhan K, Rennie MJ, Larvin M, Lund JN, Williams JP. Effect of colon cancer and surgical resection on skeletal muscle mitochondrial enzyme activity in colon cancer patients: a pilot study. J Cachexia Sarcopenia Muscle Mar 2013;4:71-77.

50. Ozawa J, Kurose T, Kawamata S, Yamaoka $\mathrm{K}$. Morphological changes in hind limb muscles elicited by adjuvant-induced arthritis of the rat knee. Scand J Med Sci Sports Feb 2010;20:e72-79.

51. Hartog A, Hulsman J, Garssen J. Locomotion and muscle mass measures in a murine model of collagen-induced arthritis. BMC Musculoskelet Disord 2009;10:59.

52. VDONT, Teixeira LIF, Viacava PR, Cerski MR, Xavier RM. Pathological and Molecular Changes in Skeletal Muscle of Collagen Induced Arthritis. London: The European League Against Rheumatism; 2011.

53. Filippin LI, Teixeira VN, Viacava PR, Lora PS, Xavier LL, Xavier RM. Temporal development of muscle atrophy in murine model of arthritis is related to disease severity. I Cachexia Sarcopenia Muscle Sep 2013;4:231-238.

54. Scherbakov N, von Haehling S, Anker SD, Dirnagl U, Doehner W. Stroke induced Sarcopenia: muscle wasting and disability after stroke. Int J Cardiol 2013;170:89-94.

55. Knops M, Werner CG, Scherbakov N, Fiebach J, Dreier JP, Meisel A, Heuschmann PU, Jungehulsing GJ, von Haehling S, Dirnagl U, Anker SD, Doehner W. Investigation of changes in body composition, metabolic 
profile and skeletal muscle functional capacity in ischemic stroke patients: the rationale and design of the Body Size in Stroke Study (BoSSS). J Cachexia Sarcopenia Muscle 2013;4:199-207.

56. Gariballa SE, Parker SG, Taub N Castleden M. Nutritional status of hospitalized acute stroke patients. Br J Nutr 1998;79:481-487.

57. Yoo SH, Kim JS, Kwon SU, Yun SC, Koh JY, Kang DW. Undernutrition as a predictor of poor clinical outcomes in acute ischemic stroke patients. Arch Neurol 2008;65:39-43.

58. Carin-Levy G, Greig C, Young A, Lewis S, Hannan J, Mead G. Longitudinal changes in muscle strength and mass after acute stroke. Cerebrovasc Dis 2006;21:201-207.

59. Jorgensen L, Jacobsen BK. Changes in muscle mass, fat mass, and bone mineral content in the legs after stroke: a 1 year prospective study. Bone 2001;28:655-659.

60. Hafer-Macko CE, Yu S, Ryan AS, Ivey FM, Macko RF. Elevated tumor necrosis factor-alpha in skeletal muscle after stroke. Stroke 2005;36:2021-2023.

61. Lu LF, Yang SS, Wang CP, Hung WC, Yu TH, Chiu CA, Chung FM, Shin SJ, Lee YJ. Elevated visfatin/pre-B-cell colony-enhancing factor plasma concentration in ischemic stroke. $J$ Stroke Cerebrovasc Dis 2009;18:354-359.

62. Heymsfield SB, Adamek M, Gonzalez MC, Jia G, Thomas DM. Assessing skeletal muscle mass: historical overview and state of the art. J Cachexia Sarcopenia Muscle 2014;5:9-18.

63. Scharf G, Heineke J. Finding good biomarkers for sarcopenia. J Cachexia Sarcopenia Muscle Sep 2012;3:145-148.

64. Cesari $M$, Fielding RA, Pahor $M$, Goodpaster B, Hellerstein $M$, van Kan GA, Anker SD, Rutkove S, Vrijbloed JW, Isaac M, Rolland $\mathrm{Y}, \mathrm{M}^{\prime}$ Rini $\mathrm{C}$, AubertinLeheudre $M$, Cedarbaum JM, Zamboni M, Sieber CC, Laurent D, Evans WJ, Roubenoff R, Morley JE, Vellas B. Biomarkers of sarcopenia in clinical trialsrecommendations from the International Working Group on Sarcopenia. J Cachexia Sarcopenia Muscle 2012;3:181-190.

65. Goodman MJ, Ghate SR, Mavros P, Sen S, Marcus RL, Joy E, Brixner DI. Development of a practical screening tool to predict low muscle mass using NHANES 1999-2004. J Cachexia Sarcopenia Muscle 2013:4:187-197.

66. Patel SS, Molnar MZ, Tayek JA, Ix JH, Noori N, Benner D, Heymsfield S, Kopple JD, Kovesdy CP, Kalantar-Zadeh K. Serum creatinine as a marker of muscle mass in chronic kidney disease: results of a cross-sectional study and review of literature. J Cachexia Sarcopenia Muscle 2013;4:19-29.

67. Nedergaard A, Karsdal MA, Sun S, Henriksen K. Serological muscle loss biomarkers: an overview of current concepts and future possibilities. J Cachexia Sarcopenia Muscle 2013;4:1-17.

68. Nedergaard A, Sun $S$, Karsdal MA, Henriksen K, Kjaer M, Lou Y, He Y, Zheng $\mathrm{Q}$, Suetta C. Type VI collagen turnover- related peptides-novel serological biomarkers of muscle mass and anabolic response to loading in young men. $J$ Cachexia Sarcopenia Muscle 2013; 4:267-275.

69. Fragala MS, Jajtner AR, Beyer KS, Townsend JR, Emerson NS, Scanlon TC, Oliveira LP, Hoffman JR, Stout JR. Biomarkers of muscle quality: N-terminal propeptide of type III procollagen and Cterminal agrin fragment responses to resistance exercise training in older adults. J Cachexia Sarcopenia Muscle 2013;5:139-148.

70. Sheffield-Moore M, Dillon EL, Randolph KM, Casperson SL, White GR, Jennings $\mathrm{K}$, Rathmacher J, Schuette S, Janghorbani M, Urban RJ, Hoang V, Willis M, Durham WJ. Isotopic decay of urinary or plasma 3methylhistidine as a potential biomarker of pathologic skeletal muscle loss. J Cachexia Sarcopenia Muscle 2013;5:19-25.

71. Abstracts of the 7th Cachexia Conference, Kobe/Osaka, Japan, December 9-11, 2013. J Cachexia Sarcopenia Muscle 2013;4:295-343.

72. Kalinkovich A, Livshits G. Sarcopenia-the search for emerging biomarkers. Ageing Res Rev 2015;22:58-71.

73. Mondello $\mathrm{P}$, Lacquaniti $\mathrm{A}$, Mondello $\mathrm{S}$ Bolignano D, Pitini V, Aloisi C, Buemi M. Emerging markers of cachexia predict survival in cancer patients. BMC Cancer 2014;14:828

74. Stephens NA, Skipworth RJE, Gallagher IJ, Greig CA, Guttridge DC, Ross JA, Fearon $\mathrm{KCH}$. Evaluating potential biomarkers of cachexia and survival in skeletal muscle of upper gastrotestinal cancer patients. J Cachexia Sarcopenia Muscle 2015;6:53-61.

75. Wu YY1, Chao TY, Liu HY, Huang TC, Chen JH, Dai MS, Janckila A, Lai SW, Chang PY. The correlation between a chronic inflammatory marker Tartrate-resistant acid phosphatase $5 \mathrm{a}$ with cancer cachexia. $J$ BUON 2015;20:325-331.

76. Janckila AJ, Neustadt DH, Nakasato YR, Halleen JM, Hentunen T, Yam LT. Serum tartrate-resistant acid phosphatase isoforms in rheumatoid arthritis. Clin Chim Acta 2002;320:49-58.

77. Janckila AJ, Lin HF, Wu YY, Ku CH, Yang SP, Lin WS, Lee SH, Yam LT, Chao TY. Serum tartrate-resistant acid phosphatase isoform 5a (TRACP5a) as a potential risk marker in cardiovascular disease. Clin Chim Acta 2011;412:963-969.

78. Wu YY, Janckila AJ, Slone SP, Perng WC, Chao TY. Tartrate-resistant acid phosphatase $5 a$ in sarcoidosis: further evidence for a novel macrophage biomarker in chronic inflammation. J Formos Med Assoc 2014;113:364-370.

79. Stimpson SA, Turner SM, Clifton LG, Poole JC, Mohammed HA, Shearer TW, Waitt GM, Hagerty LL, Remlinger KS, Hellerstein MK, Evans WJ. Total-body creatine pool size and skeletal muscle mass determination by creatine-(methylD3) dilution in rats. J Appl Physiol (1985) 2012;112:1940-1948.
80. Stimpson SA, Leonard MS, Clifton LG, Poole JC, Turner SM, Shearer TW, Remlinger KS, Clark RV, Hellerstein MK, Evans WJ. Longitudinal changes in total body creatine pool size and skeletal muscle mass using the $D_{3}$-creatine dilution method. J Cachexia Sarcopenia Muscle 2013;4(3):217-223.

81. Bhasin S, He EJ, Kawakubo M, Schroeder ET, Yarasheski K, Opiteck GJ, Reicin A, Chen F, Lam R, Tsou JA, Castaneda-Sceppa C, Binder EF, Azen SP, Sattler FR. N-terminal propeptide of type III procollagen as a biomarker of anabolic response to recombinant human GH and testosterone. J Clin Endocrinol Metab 2009;94:4224-4233.

82. Elzinga $\mathrm{M}$, Collins $\mathrm{JH}$, Kuehl WM, Adelstein RS. Complete amino-acid sequence of actin of rabbit skeletal muscle. Proc Natl Acad Sci U S A 1973;70:2687-2691.

83. Huszar G, Elzinga M. Amino acid sequence around the single 3-methylhistidine residue in rabbit skeletal muscle myosin. Biochemistry 1971;10:229-236.

84. Bilmazes C, Uauy R, Haverberg LN, Munro HN, Young VR. Musle protein breakdown rates in humans based on Ntau-methylhistidine (3-methylhistidine) content of mixed proteins in skeletal muscle and urinary output of Ntau-methylhistidine. Metabolism 1978;27:525-530.

85. Young VR, Munro HN. Ntaumethylhistidine (3-methylhistidine) and muscle protein turnover: an overview. Fed Proc 1978;37:2291-2300.

86. Ebner N, Steinbeck L, Doehner W, Anker $\mathrm{SD}$, von Haehling $\mathrm{S}$. Highlights from the 7th Cachexia Conference: muscle wasting pathophysiological detection and novel treatment strategies. I Cachexia Sarcopenia Muscle 2014;5:27-34.

87. Christensen HM, Kistorp C, Schou M, Keller N, Zerahn B, Frystyk J, Schwarz P, Faber J. Prevalence of cachexia in chronic heart failure and characteristics of body composition and metabolic status. Endocrine 2013;43:626-634.

88. Hill JJ, Davies MV, Pearson AA, Wang JH, Hewick RM, Wolfman NM, Qiu Y. The myostatin propeptide and the follistatinrelated gene are inhibitory binding proteins of myostatin in normal serum. J Biol Chem 2002;277:40735-40741.

89. Lee SJ, McPherron AC. Regulation of myostatin activity and muscle growth. Proc Natl Acad Sci U S A 2001;98:9306-9311.

90. Bostrom P, Wu J, Jedrychowski MP, Korde A, Ye L, Lo JC, Rasbach KA, Bostrom EA, Choi JH, Long JZ, Kajimura $\mathrm{S}$, Zingaretti $\mathrm{MC}$, Vind $\mathrm{BF}, \mathrm{Tu} \mathrm{H}$, Cinti $\mathrm{S}$, Hojlund K, Gygi SP, Spiegelman BM. A PGC1-alpha-dependent myokine that drives brown-fat-like development of white fat and thermogenesis. Nature 2012;481:463-468.

91. Vamvini MT, Aronis KN, Panagiotou G, Huh JY, Chamberland JP, Brinkoetter MT, Petrou M, Christophi CA, Kales SN, Christiani DC, Mantzoros CS. Irisin mRNA and circulating levels in relation to other myokines in healthy and morbidly obese humans. Eur $J$ Endocrinol 2013;169:829-834. 
92. Inui A. Cancer anorexia-cachexia syndrome: current issues in research and management. CA Cancer J Clin Mar-Apr 2002;52:72-91.

93. Deans C, Wigmore SJ. Systemic inflammation, cachexia and prognosis in patients with cancer. Curr Opin Clin Nutr Metab Care 2005;8:265-269.

94. Garcia JM, Garcia-Touza M, Hijazi RA, Taffet G, Epner D, Mann D, Smith RG, Cunningham GR, Marcelli M. Active ghrelin levels and active to total ghrelin ratio in cancer-induced cachexia. J Clin Endocrinol Metab 2005;90:2920-2926.

95. Laviano A, Gleason JR, Meguid MM, Yang Z, Cangiano C, Rossi FF. Effects of intraVMN mianserin and IL-1ra on meal number in anorectic tumor-bearing rats. J Investig Med 2000;48:40-48.

96. Mantovani G, Maccio A, Mura L, Massa E, Mudu MC, Mulas C, Lusso MR, Madeddu C, Dessi A. Serum levels of leptin and proinflammatory cytokines in patients with advanced-stage cancer at different sites. J Mol Med (Berl) 2000;78:554-561.

97. Neary NM, Small CJ, Wren AM, Lee JL, Druce MR, Palmieri C, Frost GS, Ghatei MA, Coombes RC, Bloom SR. Ghrelin increases energy intake in cancer patients with impaired appetite: acute, randomized, placebo-controlled trial. J Clin Endocrinol Metab 2004;89:2832-2836.

98. Lacquaniti A, Donato V, Chirico V, Buemi A, Buemi M. Obestatin: an interesting but controversial gut hormone. Ann Nutr Metab 2011;59:193-199.

99. Abstracts of the 7th Cachexia Conference, Kobe/Osaka, Japan, December 9-11, 2013 (part 2). J Cachexia Sarcopenia Muscle 2014;5:35-78.

100. Vaughan VC, Martin P, Lewandowski PA. Cancer cachexia: impact, mechanisms and emerging treatments. J Cachexia Sarcopenia Muscle 2013;4:95-109.

101. Morley JE, von Haehling S, Anker SD. Are we closer to having drugs to treat muscle wasting disease? J Cachexia Sarcopenia Muscle 2014;5:83-87.

102. Argiles JM, Busquets S, Lopez-Soriano FJ, Costelli $P$, Penna F. Are there any benefits of exercise training in cancer cachexia? J Cachexia Sarcopenia Muscle 2012;3:73-76.

103. Cadore EL, Izquierdo M. New strategies for the concurrent strength-, power-, and endurance-training prescription in elderly individuals. J Am Med Dir Assoc Aug 2013;14:623-624.
104. Coats AJ. Research on cachexia, sarcopenia and skeletal muscle in cardiology. J Cachexia Sarcopenia Muscle 2012;3:219-223.

105. Gould DW, Lahart I, Carmichael AR, Koutedakis Y, Metsios GS. Cancer cachexia prevention via physical exercise: molecular mechanisms. J Cachexia Sarcopenia Muscle 2013;4:111-124.

106. Silva RB, Eslick GD, Duque G. Exercise for falls and fracture prevention in long term care facilities: a systematic review and meta-analysis. J Am Med Dir Assoc Sep 2013;14:685-689 e682.

107. von Haehling S, Morley JE, Anker SD. From muscle wasting to sarcopenia and myopenia: update 2012. J Cachexia Sarcopenia Muscle Dec 2012;3:213-217.

108. Theou O, Stathokostas L, Roland KP, Jakobi JM, Patterson C, Vandervoort AA, Jones GR. The effectiveness of exercise interventions for the management of frailty: a systematic review. J Aging Res 2011;2011:569194.

109. Barbat-Artigas S, Dupontgand S, Pion $\mathrm{CH}$, Feiter-Murphy $\mathrm{Y}$, Aubertin-Leheudre $\mathrm{M}$. Identifying recreational physical activities associated with muscle quality in men and women aged 50 years and over. J Cachexia Sarcopenia Muscle 2014;5:221-228.

110. Markuns JF, Wojtaszewski JF, Goodyear $\amalg$. Insulin and exercise decrease glycogen synthase kinase-3 activity by different mechanisms in rat skeletal muscle. J Biol Chem 1999;274:24896-24900.

111. Cohen P, Goedert M. GSK3 inhibitors: development and therapeutic potential. Nat Rev Drug Discov 2004;3:479-487.

112. Cole A, Frame S, Cohen P. Further evidence that the tyrosine phosphorylation of glycogen synthase kinase-3 (GSK3) in mammalian cells is an autophosphorylation event. Biochem J 2004;377:249-255.

113. Dajani R, Fraser E, Roe SM, Young N, Good V, Dale TC, Pearl LH. Crystal structure of glycogen synthase kinase 3 beta: structural basis for phosphate-primed substrate specificity and autoinhibition. Cell 2001;105:721-732.

114. Hughes K, Nikolakaki E, Plyte SE, Totty NF, Woodgett JR. Modulation of the glycogen synthase kinase-3 family by tyrosine phosphorylation. Embo J 1993;12:803-808.

115. Lochhead PA, Kinstrie R, Sibbet G, Rawjee T, Morrice N, Cleghon V. A chaperonedependent GSK3beta transitional intermediate mediates activation-loop autophosphorylation. Mol Cell 2006;24:627-633.

116. Cross DA, Alessi DR, Cohen $P$, Andjelkovich $M$, Hemmings BA. Inhibition of glycogen synthase kinase- 3 by insulin mediated by protein kinase B. Nature 1995;378:785-789.

117. Cohen S, Nathan JA, Goldberg AL. Muscle wasting in disease: molecular mechanisms and promising therapies. Nat Rev Drug Discov 2015;14:58-74.

118. Dutt V, Gupta S, Dabur R, Injeti E, Mittal A. Skeletal muscle atrophy: potential therapeutic agents and their mechanisms of action. Pharmacol Res 2015;99:86-100.

119. Lenk K, Palus S, Schur R, Datta R, Dong J, Culler MD, Anker S, Springer J, Schuler $\mathrm{G}$, Adams V. Effect of ghrelin and its analogues, BIM-28131 and BIM-28125, on the expression of myostatin in a rat heart failure model. J Cachexia Sarcopenia Muscle 2013;4:63-69.

120. Pietra C, Takeda Y, Tazawa-Ogata N, Minami $M$, Yuanfeng $X$, Duus EM, Northrup R. Anamorelin $\mathrm{HCl}$ (ONO7643), a novel ghrelin receptor agonist, for the treatment of cancer anorexiacachexia syndrome: preclinical profile. J Cachexia Sarcopenia Muscle 2014;5: 329-337.

121. Potsch MS, Tschirner A, Palus S, von Haehling S, Doehner W, Beadle J, Coats AJ, Anker SD, Springer J. The anabolic catabolic transforming agent (ACTA) espindolol increases muscle mass and decreases fat mass in old rats. J Cachexia Sarcopenia Muscle 2014;5:149-158.

122. Stewart Coats AJ, Srinivasan V, Surendran J, Chiramana $\mathrm{H}$, Vangipuram SR, Bhatt NN, Jain M, Shah S, Ali IA, Fuang HG, Hassan MZ, Beadle J, Tilson J, Kirwan BA, Anker SD. The ACT-ONE trial, a multicentre, randomised, double-blind, placebo-controlled, dose-finding study of the anabolic/catabolic transforming agent, MT-102 in subjects with cachexia related to stage III and IV non-small cell lung cancer and colorectal cancer: study design. J Cachexia Sarcopenia Muscle 2011;2:201-207.

123. Toledo $M$, Springer J, Busquets $S$, Tschirner A, Lopez-Soriano FJ, Anker SD, Argiles JM. Formoterol in the treatment of experimental cancer cachexia: effects on heart function. J Cachexia Sarcopenia Muscle 2014;5:315-320.

124. Mirza KA, Pereira SL, Edens NK, Tisdale MJ. Attenuation of muscle wasting in murine C2C 12 myotubes by epigallocatechin-3gallate. J Cachexia Sarcopenia Muscle 2014;5:339-345.

125. Wang H, Lai YJ, Chan YL, Li TL, Wu CJ. Epigallocatechin-3-gallate effectively attenuates skeletal muscle atrophy caused by cancer cachexia. Cancer Lett 2011;305:40-49. 